\title{
Studies on the Synthesis of Gymnodimine. Construction of the Spiroimine Portion via Diels-Alder Cycloaddition
}

\author{
James D. White, ${ }^{*}$ Guo-Qiang Wang, and Laura Quaranta \\ Department of Chemistry, Oregon State University, Corvallis, OR 97331-4003
}

\section{SUPPORTING INFORMATION}




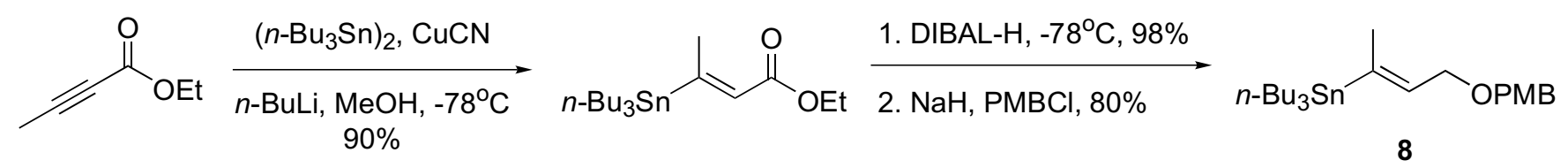

(E)-1-(4-Methoxybenzyloxy)-3-tri-n-butylstannyl-2-butene (8). To a solution of hexabutylditin $(10.0 \mathrm{~g}, 17.20 \mathrm{mmol})$ in dry THF $(70 \mathrm{~mL})$ was added $n$-BuLi $(10.8 \mathrm{~mL}$ of a $1.6 \mathrm{M}$ solution in hexane, $17.28 \mathrm{mmol}$ ) at $-20{ }^{\circ} \mathrm{C}$ under argon. The pale yellow mixture was stirred at $-20{ }^{\circ} \mathrm{C}$ for $30 \mathrm{~min}$, and cooled to $-50{ }^{\circ} \mathrm{C}$. $\mathrm{CuCN}(1.54 \mathrm{~g}, 17.21 \mathrm{mmol})$ was added, and the resulting mixture was stirred for 30 min to give an orange colored solution of the cuprate reagent. The solution was cooled to $-100{ }^{\circ} \mathrm{C}$, and a solution of ethyl 2-butynoate $(1.61 \mathrm{~g}, 14.40 \mathrm{mmol})$ in dry EtOH $(890 \mu \mathrm{L}, 15.7 \mathrm{mmol})$ and dry THF $(10 \mathrm{~mL})$ was added via cannula during $10 \mathrm{~min}$. The resulting mixture was stirred for $4 \mathrm{~h}$ at $-78{ }^{\circ} \mathrm{C}$. The reaction was quenched by addition of saturated, aqueous $\mathrm{NH}_{4} \mathrm{Cl}$, and the mixture was allowed to warm to room temperature. The mixture was diluted with $\mathrm{Et}_{2} \mathrm{O}$. The phases were separated, and the aqueous layer was extracted with $\mathrm{Et}_{2} \mathrm{O}$ twice. The combined organic layer was washed with brine, dried over $\mathrm{Na}_{2} \mathrm{SO}_{4}$, and concentrated in vacuo. Flash chromatography (AcOEt-hexane, 1:50) of the residue afforded $5.28 \mathrm{~g}(90 \%)$ of ethyl (E)-3-tri-n-butylstannylcrotonate: IR (neat) 2957, 2927, 2872, 1715, 1599, 1464, 1338, 1175, 1039, $863 \mathrm{~cm}^{-1} ;{ }^{1} \mathrm{H}$ NMR $\left(300 \mathrm{MHz}, \mathrm{CDCl}_{3}\right) \delta 0.85-1.05(\mathrm{~m}, 6 \mathrm{H}), 0.90(\mathrm{t}, J=$ $7.2 \mathrm{~Hz}, 9 \mathrm{H}), 1.26-1.38(\mathrm{~m}, 6 \mathrm{H}), 1.30(\mathrm{t}, J=7.1 \mathrm{~Hz}, 3 \mathrm{H}), 1.46-1.56(\mathrm{~m}, 6 \mathrm{H}), 2.33-1.48(\mathrm{~m}, 3 \mathrm{H})$, $4.17(\mathrm{q}, J=7.1 \mathrm{~Hz}, 2 \mathrm{H}), 5.85-6.07(\mathrm{~m}, 1 \mathrm{H}) ;{ }^{13} \mathrm{C} \mathrm{NMR}\left(100 \mathrm{Mz}, \mathrm{CDCl}_{3}\right) \delta 9.8,14.0,14.8,22.8,27.7$, 29.4, 59.9, 128.5, 164.8, 169.5; HRMS (CI) $m / z 405.1812\left([\mathrm{M}+\mathrm{H}]^{+}\right.$; calcd for $\mathrm{C}_{18} \mathrm{H}_{37} \mathrm{O}_{2}{ }^{120} \mathrm{Sn}$ : 405.1815).

To the crotonate prepared above $(2.22 \mathrm{~g}, 5.50 \mathrm{mmol})$ in dry THF $(50 \mathrm{~mL})$ at $-78{ }^{\circ} \mathrm{C}$ under argon was added dropwise neat diisobutylaluminum hydride $(2.35 \mathrm{~mL}, 13.20 \mathrm{mmol})$. The mixture was stirred at $-78{ }^{\circ} \mathrm{C}$ for $2.5 \mathrm{~h}$, then was quenched with a $1 \mathrm{M}$ aqueous solution of sodium potassium tartrate $(20$ $\mathrm{mL}$ ). The phases were separated and the aqueous layer was extracted with $\mathrm{Et}_{2} \mathrm{O}$ twice. The combined organic layer was washed with brine, dried over $\mathrm{MgSO}_{4}$, and concentrated in vacuo. Flash chromatography ( $\mathrm{Et}_{2} \mathrm{O}-$ hexane, 1:4) of the residue afforded 1.95 (98\%) of an alcohol: IR (neat) 3305, 
2926, 2867, 1457, 1381, 1061, 1006, $876 \mathrm{~cm}^{-1} ;{ }^{1} \mathrm{H}$ NMR $\left(300 \mathrm{MHz}, \mathrm{CDCl}_{3}\right) \delta 0.79-1.01(\mathrm{~m}, 6 \mathrm{H}), 0.90$ $(\mathrm{t}, J=7.2 \mathrm{~Hz}, 9 \mathrm{H}), 1.26-1.38(\mathrm{~m}, 6 \mathrm{H}), 1.45-1.56(\mathrm{~m}, 6 \mathrm{H}), 1.82-1.97(\mathrm{~m}, 3 \mathrm{H}), 4.26(\mathrm{t}, J=5.6 \mathrm{~Hz}$, 2H), $5.88-5.65(\mathrm{~m}, 1 \mathrm{H}) ;{ }^{13} \mathrm{C}$ NMR $\left(100 \mathrm{Mz}, \mathrm{CDCl}_{3}\right) \delta 9.5,14.1,19.8,27.8,29.5,59.2,139.7,142.8$; HRMS (CI) $m / z 365.1547\left([\mathrm{M}-\mathrm{H}]^{+}\right.$; calcd for $\left.\mathrm{C}_{16} \mathrm{H}_{33} \mathrm{O}^{120} \mathrm{Sn}: 365.1553\right)$.

To a suspension of $\mathrm{NaH}(0.41 \mathrm{~g}, 17.08 \mathrm{mmol})$ in dry DMF $(20 \mathrm{~mL})$ at $0{ }^{\circ} \mathrm{C}$ was added a solution of the alcohol prepared above $(3.61 \mathrm{~g}, 9.88 \mathrm{mmol})$ in dry DMF $(20 \mathrm{~mL})$. The resulting mixture was stirred for $20 \mathrm{~min}$ at $0{ }^{\circ} \mathrm{C}$, 4-methoxylbenzyl chloride $(1.90 \mathrm{ml}, 14.01 \mathrm{mmol})$ was added, and the mixture was stirred overnight at room temperature. The reaction was quenched by addition of saturated, aqueous $\mathrm{NH}_{4} \mathrm{Cl}$, and the mixture was diluted with $\mathrm{Et}_{2} \mathrm{O}$. The phases were separated and the aqueous layer was extracted with $\mathrm{Et}_{2} \mathrm{O}$ twice. The organic layer was washed with water and brine, dried over $\mathrm{Na}_{2} \mathrm{SO}_{4}$, and concentrated in vacuo. Flash chromatography (Et $\mathrm{E}_{2} \mathrm{O}$-hexane, 1:50) of the residue afforded $3.85 \mathrm{~g}(80 \%)$ of 8: IR (neat) 2955, 2925, 2851, 1613, 1513,1248, 1087, 1039, 818cm ${ }^{-1} ;{ }^{1} \mathrm{H}$ NMR $\left(300 \mathrm{MHz}, \mathrm{CDCl}_{3}\right) 0.85(\mathrm{t}, J=7.3 \mathrm{~Hz}, 9 \mathrm{H}), 0.85(\mathrm{~m}, 6 \mathrm{H}), 1.30(\mathrm{~m}, 6 \mathrm{H}), 1.45(\mathrm{~m}, 6 \mathrm{H}), 1.72-1.92(\mathrm{~m}, 3 \mathrm{H})$, $3.79(\mathrm{~s}, 3 \mathrm{H}), 4.15(\mathrm{~m}, 2 \mathrm{H}), 4.43(\mathrm{~s}, 2 \mathrm{H}), 5.65-5.84(\mathrm{~m}, 1 \mathrm{H}), 6.65(\mathrm{~m}, 2 \mathrm{H}), 7.25(\mathrm{~m}, 2 \mathrm{H}) ;{ }^{13} \mathrm{C} \mathrm{NMR}$ $\left(100 \mathrm{Mz}, \mathrm{CDCl}_{3}\right) 9.5,14.1,20.0,27.8,29.6,55.7,66.3,72.1,114.2,129.9,131.0,137.3,143.5,159.8 ;$ $\operatorname{HRMS}(\mathrm{CI}) m / z 481.2117\left([\mathrm{M}-\mathrm{H}]^{+}\right.$cacld for $\left.\mathrm{C}_{24} \mathrm{H}_{41} \mathrm{O}_{2}{ }^{120} \mathrm{Sn}: 481.2128\right)$.

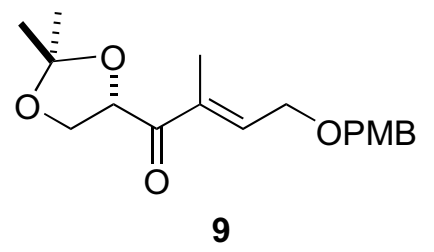

(4S)-(E)-1-(2,2-Dimethyl-[1,3]dioxolan-4-yl)-4-(4-methoxybenzyloxy)-2-methylbut-2-en-1-one (9). To a solution of $8(2.73 \mathrm{~g}, 5.67 \mathrm{mmol})$ in dry THF $(10 \mathrm{~mL})$ at $-78{ }^{\circ} \mathrm{C}$ under argon was added $n$ BuLi (3.15 mL of a 1.8M solution in hexane, $5.68 \mathrm{mmol})$ during $45 \mathrm{~min}$. After stirring for $1 \mathrm{~h}$, the yellow solution was transferred via cannula to a solution of 7 (1.07 g, $5.67 \mathrm{mmol})$ in dry THF (10 mL) that was precooled to $-78{ }^{\circ} \mathrm{C}$. and the mixture was stirred for $1.5 \mathrm{~h}$ at $-78{ }^{\circ} \mathrm{C}$. The reaction was quenched by addition of saturated aqueous $\mathrm{NH}_{4} \mathrm{Cl}$ and the mixture was diluted with $\mathrm{Et}_{2} \mathrm{O}$. The phases 
were separated and the aqueous phase was extracted with $\mathrm{Et}_{2} \mathrm{O}$. The organic layer was washed with brine, dried over $\mathrm{Na}_{2} \mathrm{SO}_{4}$, filtered, and concentrated in vacuo. Flash chromatography (hexane-ethyl acetate, $4: 1)$ of the residue afforded $1.28 \mathrm{~g}(71 \%)$ of 9 as a colorless oil: $[\alpha]_{\mathrm{D}}^{23}-23.5\left(\mathrm{c} 1.3, \mathrm{CHCl}_{3}\right)$; IR (neat) $2987,2936,2903,2867,2836,1685,1612,1513,1457,1372,1248,1213,1067,911,844 \mathrm{~cm}^{-1}$; ${ }^{1} \mathrm{H}$ NMR $\left(300 \mathrm{MHz}, \mathrm{CDCl}_{3}\right) \delta 1.42(\mathrm{~s}, 3 \mathrm{H}), 1.43(\mathrm{~s}, 3 \mathrm{H}), 1.77(\mathrm{~d}, J=1.2 \mathrm{~Hz}, 3 \mathrm{H}), 3.82(\mathrm{~s}, 3 \mathrm{H}), 4.07$ $(\mathrm{dd}, J=6.3,8.3 \mathrm{~Hz}, 1 \mathrm{H}), 4.21(\mathrm{dd}, J=7.3,8.4 \mathrm{~Hz}, 1 \mathrm{H}), 4.26(\mathrm{~d}, J=5.2 \mathrm{~Hz}, 2 \mathrm{H}), 4.5(\mathrm{~s}, 2 \mathrm{H}), 5.06(\mathrm{dd}, J$ $=6.4,7.1 \mathrm{~Hz}, 1 \mathrm{H}), 6.73(\mathrm{td}, J=1.2,5.4 \mathrm{~Hz}, 1 \mathrm{H}), 6.82(\mathrm{~m}, 2 \mathrm{H}), 7.25(\mathrm{~m}, 2 \mathrm{H}) ;{ }^{13} \mathrm{C} \mathrm{NMR}(100 \mathrm{Mz}$, $\left.\mathrm{CDCl}_{3}\right) \delta 12.3,26.0,26.3,55.7,67.1,67.4,73.2,76.9,111.2,114.3,130.0,136.2,141.6,159.9,197.3 ;$ HRMS (CI) $m / z 321.1700\left([\mathrm{M}+\mathrm{H}]^{+}\right.$; calcd for $\left.\mathrm{C}_{18} \mathrm{H}_{25} \mathrm{O}_{5}: 321.1702\right)$.

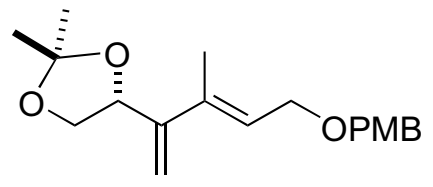

10

\section{(4R)-(E)-4-[4-(4-Methoxybenzyloxy)-2-methyl-1-methylenebut-2-enyl]-2,2-dimethyl-}

[1,3]dioxolane (10). To a suspension of methyltriphenylphosphonium bromide $(7.84 \mathrm{~g}, 21.6 \mathrm{mmol})$ in dry THF $(60 \mathrm{~mL})$ at $-78{ }^{\circ} \mathrm{C}$ under argon was added $n$-BuLi $(10.45 \mathrm{~mL}$ of a $1.98 \mathrm{M}$ solution in hexane, $20.7 \mathrm{mmol})$. The mixture was warmed to $0{ }^{\circ} \mathrm{C}$ and stirred for 1 . The mixture was cooled to $-78{ }^{\circ} \mathrm{C}$ again, and a solution of $9(6.30 \mathrm{~g}, 19.7 \mathrm{mmol})$ in THF $(40 \mathrm{~mL})$ was added slowly. The resulting mixture was allowed to warm to $0{ }^{\circ} \mathrm{C}$ and stirred for $5 \mathrm{~h}$. The reaction was quenched by addition of saturated aqueous $\mathrm{NH}_{4} \mathrm{Cl}$, and the mixture was diluted with $\mathrm{Et}_{2} \mathrm{O}$. The phases were separated and the aqueous phase was extracted with $\mathrm{Et}_{2} \mathrm{O}$. The organic phase was washed with brine, dried over $\mathrm{Na}_{2} \mathrm{SO}_{4}$, and concentrated in vacuo. Flash chromatography (hexane-ethyl acetate, 10:1) of the residue afforded 5.25 $\mathrm{g}(84 \%)$ of 10: $[\alpha]_{\mathrm{D}}^{23}-34.2$ (c 1.15, $\left.\mathrm{CHCl}_{3}\right)$; IR (neat) 2997, 2938, 2850, 1608, 1511, 1456, 1368, 1296, 1241, 1170, 1060, 1039, $824 \mathrm{~cm}^{-1} ;{ }^{1} \mathrm{H}$ NMR (300 MHz, $\left.\mathrm{CDCl}_{3}\right) \delta 1.43(\mathrm{~s}, 3 \mathrm{H}), 1.48(\mathrm{~s}, 3 \mathrm{H}), 1.81(3 \mathrm{H})$, $3.55(\mathrm{t}, J=7.8 \mathrm{~Hz}, 1 \mathrm{H}), 3.80(\mathrm{~s}, 3 \mathrm{H}), 4.14(\mathrm{~d}, J=6.2 \mathrm{~Hz}, 1 \mathrm{H}), 4.27(\mathrm{dd}, J=6.6,8.0 \mathrm{~Hz}, 1 \mathrm{H}), 4.45(\mathrm{~s}$, 
2H), $4.89(\mathrm{t}, J=7.0 \mathrm{~Hz}, 1 \mathrm{H}), 5.21(\mathrm{~s}, 1 \mathrm{H}), 5.46(\mathrm{~s}, 1 \mathrm{H}), 5.55(\mathrm{t}, J=6.0 \mathrm{~Hz}, 1 \mathrm{H}), 6.87(\mathrm{~m}, 2 \mathrm{H}), 7.26(\mathrm{~m}$, $2 \mathrm{H}) ;{ }^{13} \mathrm{C} \mathrm{NMR}\left(100 \mathrm{Mz}, \mathrm{CDCl}_{3}\right) \delta 15.4,26.0,26.7,55.7,67.2,70.9,72.6,75.7,109.4,111.4,114.3$, 124.5, 129.9, 130.6, 136.2, 147.2, 159.7; HRMS (CI) $\mathrm{m} / z$ 318.1830 ([M] $]^{+}$; calcd for $\mathrm{C}_{19} \mathrm{H}_{26} \mathrm{O}_{4}$ : $318.1831)$.

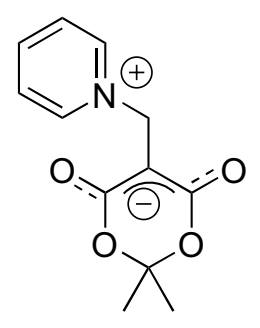

13

1-[(6-Hydroxy-2,2-dimethyl-4-oxo-4H-1,3-dioxin-5-yl)methyl]pryridinium hydroxide, inner salt (13). Meldrum's acid (5.41 g, $27.5 \mathrm{mmol})$ was dissolved in dry pyridine (35 $\mathrm{mL})$ and to the colorless solution was added formaldehyde $(2.80 \mathrm{~mL}$ of a $37 \%$ aqueous solution, $37.5 \mathrm{mmol})$ in one portion at room temperature. The yellow mixture was stirred for $2 \mathrm{~h}$ and the solvent was removed under vacuum at $55{ }^{\circ} \mathrm{C}$. The precipitate was collected and washed with hexane $(100 \mathrm{~mL})$ to give pure $\mathbf{1 3}$ as a pale yellow solid. This material was dried under vacuum overnight to provide $8.20 \mathrm{~g}(93 \%)$ of $13:{ }^{1} \mathrm{H}$ NMR $\left(400 \mathrm{MHz}, \mathrm{CDCl}_{3}\right) \delta 1.64(\mathrm{~s}, 6 \mathrm{H}), 5.57(\mathrm{br} \mathrm{s}, 2 \mathrm{H}), 7.73(\mathrm{t}, J=6.6 \mathrm{~Hz}, 2 \mathrm{H}), 8.16(\mathrm{t}, J=7.5 \mathrm{~Hz}$, 2H), $8.99(\mathrm{~d}, J=5.5 \mathrm{~Hz}, 1 \mathrm{H})$.

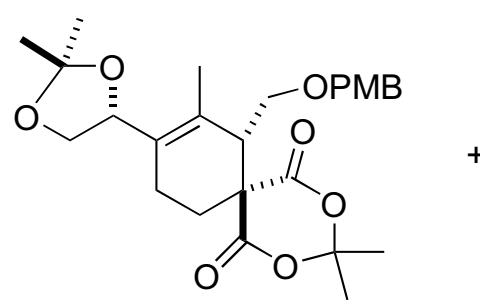

14

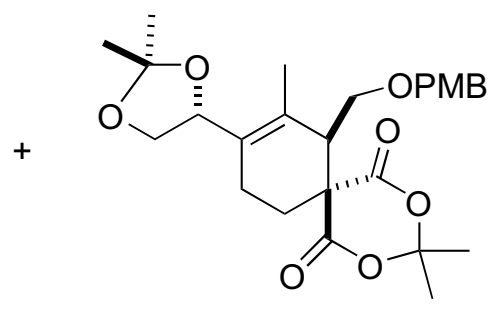

15

$14: 15=1.2: 1$

\section{9-(2',2'-Dimethyl-[1',3']dioxolan-4'-yl)-7-(4''-methoxybenzyloxymethyl)-3,3,8-trimethyl-2,4-}

dioxa-spiro[5.5] undec-8-ene-1,5-diones (14 and 15). To a solution of 13 (172 $\mathrm{mg}, 0.54 \mathrm{mmol})$ in anhydrous EtOH $(8 \mathrm{~mL})$ at room temperature under argon was added glacial acetic acid $(37 \mu \mathrm{L}, 0.65$ mmol). A solution of $\mathbf{1 0}(153 \mathrm{mg}, 0.65 \mathrm{mmol})$ in EtOH $(4 \mathrm{~mL})$ was added slowly via cannula, and the mixture was stirred for $48 \mathrm{~h}$ at room temperature. After removal of the solvent, the residue was diluted 
with cold water and EtOAc. The organic layer was separated, washed with brine, dried over $\mathrm{Na}_{2} \mathrm{SO}_{4}$, filtered, and concentrated under vacuum. Flash chromatography (hexane-ethyl acetate, 1:1) of the residue afforded $217 \mathrm{mg}(85 \%)$ of a mixture (1.2:1) of $\mathbf{1 4}$ and $\mathbf{1 5}$. The mixture was separated by preparative layer chromatography (Chromatotron, $\mathrm{CH}_{2} \mathrm{Cl}_{2}$-EtOAc, 100:5) to provide pure $\mathbf{1 4}$ and $\mathbf{1 5}$.

$\left(\mathbf{4}^{\prime} \boldsymbol{R}, \mathbf{7 S}\right)-\mathbf{1 4}:[\alpha]_{\mathrm{D}}^{23}+8.6\left(\mathrm{c} 1.05, \mathrm{CHCl}_{3}\right)$; IR (mixture) (neat) 2986, 2936, 2873, 1770, 1736, 1613, 1514, 1456, 1379, 1304, 1278, 1249, 1209, 1157, 1055, 1033, 860, 822, $735 \mathrm{~cm}^{-1} ;{ }^{1} \mathrm{H}$ NMR $(300 \mathrm{MHz}$, $\left.\mathrm{CDCl}_{3}\right) \delta 1.35(\mathrm{~s}, 3 \mathrm{H}), 1.38(\mathrm{~s}, 3 \mathrm{H}), 1.41(\mathrm{~s}, 3 \mathrm{H}), 1.61(\mathrm{~s}, 3 \mathrm{H}), 1.69(\mathrm{~s}, 3 \mathrm{H}), 1.97(\mathrm{~m}, 1 \mathrm{H}), 2.08-2.32$ (m, 3H), $3.44(\mathrm{dd}, J=8.0,11.2 \mathrm{~Hz}, 1 \mathrm{H}), 3.45(\mathrm{t}, J=8.0 \mathrm{~Hz}, 1 \mathrm{H}), 3.58(\mathrm{~m}, 1 \mathrm{H}), 3.77(\mathrm{~s}, 3 \mathrm{H}), 3.76(\mathrm{~m}$, 1H), $4.05(\mathrm{dd}, J=7.0,8.0 \mathrm{~Hz}, 1 \mathrm{H}), 4.34(\mathrm{~s}, 2 \mathrm{H}), 5.01(\mathrm{t}, J=7.0 \mathrm{~Hz}, 1 \mathrm{H}), 6.83(\mathrm{~m}, 2 \mathrm{H}), 7.18(\mathrm{~m}, 2 \mathrm{H})$; ${ }^{13} \mathrm{C}$ NMR $\left(100 \mathrm{Mz}, \mathrm{CDCl}_{3}\right) \delta 16.7,21.1,25.7,26.8,28.9,29.8,31.8,45.7,50.2,55.6,67.8,68.5,73.4$, 75.2, 105.7, 109.5, 114.1, 127.0, 129.6, 129.8, 129.9, 159.6, 165.5, 170.7; HRMS (mixture) (CI) $\mathrm{m} / \mathrm{z}$ 474.2249 ([M] $]^{+}$; calcd for $\left.\mathrm{C}_{26} \mathrm{H}_{34} \mathrm{O}_{8}: 474.2254\right)$.

$\left(\mathbf{4}^{\prime} \boldsymbol{R}, 7 \boldsymbol{R}\right)$ 15: $[\alpha]_{\mathrm{D}}^{23}-10.4\left(\mathrm{c} 0.5, \mathrm{CHCl}_{3}\right)$; IR (mixture) (neat) 2986, 2936, 2873, 1770, 1736, 1613, $1514,1456,1379,1304,1278,1249,1209,1157,1055,1033,860,822,735 \mathrm{~cm}^{-1} ;{ }^{1} \mathrm{H}$ NMR $(300 \mathrm{MHz}$, $\left.\mathrm{CDCl}_{3}\right) \delta 1.36(\mathrm{~s}, 3 \mathrm{H}), 1.39(\mathrm{~s}, 3 \mathrm{H}), 1.43(\mathrm{~s}, 3 \mathrm{H}), 1.67(\mathrm{~s}, 3 \mathrm{H}), 1.71(\mathrm{~s}, 3 \mathrm{H}), 1.98-2.27(\mathrm{~m}, 3 \mathrm{H}), 2.39-$ $2.53(\mathrm{~m}, 1 \mathrm{H}), 3.37(\mathrm{~m}, 1 \mathrm{H}), 3.65(\mathrm{t}, J=8.0 \mathrm{~Hz}, 1 \mathrm{H}), 3.79(\mathrm{~s}, 3 \mathrm{H}), 3.70-3.82(\mathrm{~m}, 2 \mathrm{H}), 4.00(\mathrm{t}, J=8.0$ $\mathrm{Hz}, 1 \mathrm{H}), 4.37(\mathrm{~m}, 2 \mathrm{H}), 5.04(\mathrm{t}, J=7.0 \mathrm{~Hz}, 1 \mathrm{H}), 6.85(\mathrm{~d}, J=7.9 \mathrm{~Hz}, 2 \mathrm{H}), 7.18(\mathrm{~d}, J=7.8 \mathrm{~Hz}, 2 \mathrm{H}) ;{ }^{13} \mathrm{C}$ $\operatorname{NMR}\left(100 \mathrm{Mz}, \mathrm{CDCl}_{3}\right) \delta 16.4,20.1,26.0,26.7,28.9,29.7,31.8,45.7,50.3,55.7,67.5,68.9,73.5,74.3$, 105.7, 109.4, 114.1, 128.5, 129.2, 129.7, 129.9, 159.7, 165.5, 170.7; HRMS (mixture) (CI) $\mathrm{m} / \mathrm{z}$ 474.2249 ([M] $]^{+}$; calcd for $\left.\mathrm{C}_{26} \mathrm{H}_{34} \mathrm{O}_{8}: 474.2254\right)$.

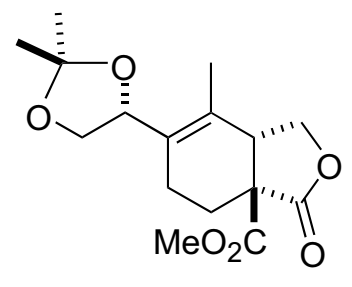

16 
(3aR,7aS,4'R)-6-(2',2'-Dimethyl-[1',3']dioxolan-4'-yl)-7-methyl-3-oxo-1,4,5,7a-tetrahydro-

isobenzofuran-3a-carboxylic Acid Methyl Ester (16). To a solution of 14 (145 $\mathrm{mg}, 0.30 \mathrm{mmol})$ in a mixture of $\mathrm{CH}_{2} \mathrm{Cl}_{2}(8 \mathrm{~mL})$ and $\mathrm{pH} 7$ buffer $(0.4 \mathrm{~mL})$ under argon at room temperature was added DDQ (82 $\mathrm{mg}, 0.36 \mathrm{mmol}$ ). The mixture was stirred for $3 \mathrm{~h}$, then was cooled to $0{ }^{\circ} \mathrm{C}$ and (trimethylsilyl)diazomethane $(2.0 \mathrm{~mL}$ of a $2 \mathrm{M}$ solution in hexane, $4 \mathrm{mmol})$ was added carefully. The resulting mixture was allowed to warm to room temperature and was stirred overnight. The mixture was diluted with toluene $(5 \mathrm{~mL})$ and the solvent was removed under reduced pressure to leave a residue which was purified by flash chromatography ( $\mathrm{Et}_{2} \mathrm{O}$-hexane, 1:1) to provide $73 \mathrm{mg}(78 \%)$ of 16 as a colorless solid: $\mathrm{mp} 128-129{ }^{\circ} \mathrm{C}$; $[\alpha]_{\mathrm{D}}^{23}-141.5$ (c 0.4, $\mathrm{CHCl}_{3}$ ); IR (neat) 2986, 2932, 2850, 1777, 1733, $1435,1272,1247,1205,1157,1055,1024,856 \mathrm{~cm}^{-1} ;{ }^{1} \mathrm{H}$ NMR $\left(400 \mathrm{MHz}, \mathrm{CDCl}_{3}\right) \delta 1.38(\mathrm{~s}, 3 \mathrm{H}), 1.44$ $(\mathrm{s}, 3 \mathrm{H}), 1.74(\mathrm{~s}, 3 \mathrm{H}), 1.97-2.31(\mathrm{~m}, 4 \mathrm{H}), 3.36(\mathrm{t}, J=7.2 \mathrm{~Hz}, 1 \mathrm{H}), 3.51(\mathrm{t}, J=8.1 \mathrm{~Hz}, 1 \mathrm{H}), 3.79(\mathrm{~s}$, $3 \mathrm{H}), 4.02(\mathrm{dd}, J=7.2,8.1 \mathrm{~Hz}, 1 \mathrm{H}), 4.05(\mathrm{dd}, J=6.3,9.0 \mathrm{~Hz}, 1 \mathrm{H}), 4.62(\mathrm{dd}, J=8.0,9.1 \mathrm{~Hz}, 1 \mathrm{H}), 4.98$ $(\mathrm{t}, J=7.0 \mathrm{~Hz}, 1 \mathrm{H}) ;{ }^{13} \mathrm{C}$ NMR $\left(100 \mathrm{Mz}, \mathrm{CDCl}_{3}\right) \delta 17.4,20.3,25.1,25.9,26.7,45.2,53.6,53.7,67.5$, 71.1, 74.6, 109.8, 127.3, 131.3, 170.4, 175.0 ; HRMS (FAB) $m / z$ 309.1335 ([M-H] $]^{+}$; calcd for $\mathrm{C}_{16} \mathrm{H}_{21} \mathrm{O}_{6}$ : 309.1338).

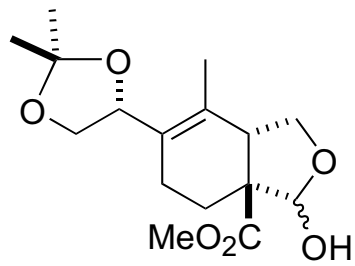

17

(3aS,7aS,4'R)-6-(2',2'-Dimethyl-[1',3']dioxolan-4'-yl)-3-hydroxy-7-methyl-1,4,5,7atetrahydroisobenzofuran-3a-carboxylic Acid Methyl Ester (17). To a solution of 16 (22 mg, 0.07 mmol) in dry THF $(1 \mathrm{~mL})$ under argon at $-35^{\circ} \mathrm{C}$ was added DIBAL-H ( $80 \mu 1$ of $1 \mathrm{M}$ solution in hexane, $0.08 \mathrm{mmol})$. The mixture was stirred at $-35^{\circ} \mathrm{C}$ for $24 \mathrm{~h}$ and the reaction was quenched by the addition of an aqueous solution of Rochelle's salt. The mixture was diluted with $\mathrm{Et}_{2} \mathrm{O}$ and was warmed to room temperature. The organic layer was separated, washed with brine, dried over $\mathrm{Na}_{2} \mathrm{SO}_{4}$, and concentrated 
under vacuum. Flash chromatography (hexane-ethyl acetate, $2: 1)$ of the residue afforded $17 \mathrm{mg}(75 \%)$ of $\mathbf{1 7}$ as a 12:1 mixture of diastereoisomers: major isomer, $[\alpha]_{D}^{23}-20.8\left(\mathrm{c} 0.36, \mathrm{CHCl}_{3}\right)$; IR (neat) 3419 , 2984, 2935, 2886, 1742, 1454, 1372, 1259, 1208, 1179, 1050, 926, $860 \mathrm{~cm}^{-1} ;{ }^{1} \mathrm{H}$ NMR $(400 \mathrm{MHz}$, $\left.\mathrm{CDCl}_{3}\right) \delta 1.39(\mathrm{~s}, 3 \mathrm{H}), 1.44(\mathrm{~s}, 3 \mathrm{H}), 1.50-1.80(\mathrm{~m}, 2 \mathrm{H}), 1.74(\mathrm{~s}, 3 \mathrm{H}), 2.22(\mathrm{~m}, 1 \mathrm{H}), 2.38(\mathrm{~m}, 1 \mathrm{H}), 2.71$ (br s, 1H), $3.38(\mathrm{t}, J=9.0 \mathrm{~Hz}, 1 \mathrm{H}), 3.56(\mathrm{t}, J=8.1 \mathrm{~Hz}, 1 \mathrm{H}), 3.70(\mathrm{t}, J=8.1 \mathrm{~Hz}, 1 \mathrm{H}), 3.73(\mathrm{~s}, 3 \mathrm{H}), 3.97$ $(\mathrm{dd}, J=7.0,8.1 \mathrm{~Hz}, 1 \mathrm{H}), 4.50(\mathrm{dd}, J=8.2,9.1 \mathrm{~Hz}, 1 \mathrm{H}), 5.02(\mathrm{t}, J=7.3 \mathrm{~Hz}, 1 \mathrm{H}), 5.25(\mathrm{~s}, 1 \mathrm{H}) ;{ }^{13} \mathrm{C} \mathrm{NMR}$ $\left(100 \mathrm{Mz}, \mathrm{CDCl}_{3}\right) \delta 18.7,20.2,26.0,26.7,43.6,52.6,57.6,67.3,73.3,74.4,103.5,109.4,127.1,130.7$, 172.8; HRMS (CI) $m / z 312.1567\left([\mathrm{M}]^{+}\right.$; calcd for $\left.\mathrm{C}_{16} \mathrm{H}_{24} \mathrm{O}_{6}: 312.1573\right)$.

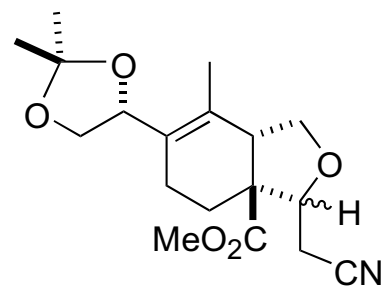

19

\section{(3aS,7aS,4'R)-3-Cyanomethyl-6-(2',2'-dimethyl-[1',3']dioxolan-4'-yl)-7-methyl-1,4,5,7a-}

tetrahydroisobenzofuran-3a-carboxylic Acid Methyl Ester To a solution of phosphonate $18(20 \mu \mathrm{L}$, $0.12 \mathrm{mmol})$ in dry THF $(0.5 \mathrm{~mL})$ at $0{ }^{\circ} \mathrm{C}$ was added $n$-BuLi ( $46 \mu \mathrm{L}$ of a $2.5 \mathrm{M}$ hexane solution, 0.12 mmol). The mixture was stirred for $10 \mathrm{~min}$ and was added slowly to a solution of $\mathbf{1 7}$ (18 $\mathrm{mg}, 0.06$ mmol) in dry THF $(0.5 \mathrm{~mL})$ at $0{ }^{\circ} \mathrm{C}$. The resulting mixture was stirred overnight at room temperature. The reaction was quenched by the addition of saturated $\mathrm{NH}_{4} \mathrm{Cl}$, and the mixture was diluted with $\mathrm{Et}_{2} \mathrm{O}$. The phases were separated, the aqueous phase was extracted with $\mathrm{Et}_{2} \mathrm{O}$ twice, and the combined organic layer was washed with brine, dried over $\mathrm{Na}_{2} \mathrm{SO}_{4}$, and concentrated under vacuum. Flash chromatography (hexane-ethyl, 3:1) of the residue afforded $17 \mathrm{mg}(86 \%)$ of 19 as a $2: 1$ mixture of diastereoisomers: IR (neat) 2984, 2933, 2882, 2253, 1732, 1454, 1437, 1382, 1370, 1261, 1212, 1057, 858, $795 \mathrm{~cm}^{-1} ;{ }^{1} \mathrm{H}$ NMR $\left(400 \mathrm{MHz}, \mathrm{CDCl}_{3}\right) \delta 1.39(\mathrm{~s}, 3 \mathrm{H}), 1.42(\mathrm{~s}, 3 \mathrm{H}), 1.60(\mathrm{~m}, 1 \mathrm{H}), 1.78-2.10(\mathrm{~m}$, 3H), $2.55(\mathrm{dd}, J=8.4,16.7 \mathrm{~Hz}, 1 \mathrm{H}), 2.75(\mathrm{dd}, J=4.3,16.7 \mathrm{~Hz}, 1 \mathrm{H}), 3.25(\mathrm{~m}, 1 \mathrm{H}), 3.51(\mathrm{~m}, 1 \mathrm{H}), 3.68$ 
$(\mathrm{dd}, J=8.1,9.0 \mathrm{~Hz}, 1 \mathrm{H}), 3.70(\mathrm{~s}, 3 \mathrm{H}), 3.98(\mathrm{~m}, 1 \mathrm{H}), 4.21(\mathrm{dd}, J=4.30,8.4 \mathrm{~Hz}, 1 \mathrm{H}), 4.32(\mathrm{dd}, J=8.1$, $10.8 \mathrm{~Hz}, 1 \mathrm{H}), 5.00(\mathrm{dd}, J=6.2,6.8 \mathrm{~Hz}, 1 \mathrm{H}) ;{ }^{13} \mathrm{C} \mathrm{NMR}\left(100 \mathrm{Mz}, \mathrm{CDCl}_{3}\right.$ ) (major isomer) $\delta 18.5,19.4$, 20.3, 21.8, 26.7, 28.5, 48.1, 53.0, 67.3, 72.8, 74.3, 80.1, 109.5, 117.7, 127.5, 129.9, 173.2, 213.0; HRMS (CI) $m / z 335.1729\left([\mathrm{M}]^{+}\right.$; calcd for $\left.\mathrm{C}_{18} \mathrm{H}_{25} \mathrm{O}_{5} \mathrm{~N}: 335.1733\right)$.

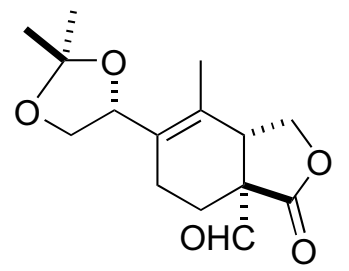

22

\section{(3aS,7aS,4'R)-6-(2',2'-Dimethyl-[1',3']dioxolan-4'-yl)-7-methyl-3-oxo-1,4,5,7a-tetrahydro-}

isobenzofuran-3a-carbaldehyde (22). To a solution of $14(312 \mathrm{mg}, 0.66 \mathrm{mmol})$ in a mixture of $\mathrm{CH}_{2} \mathrm{Cl}_{2}(6.0 \mathrm{~mL})$ and $\mathrm{pH} 7$ buffer $(0.3 \mathrm{~mL})$ at $0{ }^{\circ} \mathrm{C}$ was added DDQ (180 mg, $\left.0.79 \mathrm{mmol}\right)$. The mixture was stirred for $8 \mathrm{~h}$ at room temperature. To this mixture was added $\mathrm{NaHCO}_{3}$ powder $(224 \mathrm{mg}, 2.6$ mmol) and the solvent was removed to leave carboxylic acid 20. To a suspension of this material in a mixture of THF $(6.0 \mathrm{~mL})$ and $\mathrm{H}_{2} \mathrm{O}(0.75 \mathrm{~mL})$ at $-10{ }^{\circ} \mathrm{C}$ was added $\mathrm{NaBH}_{4}(240 \mathrm{mg}, 6.3 \mathrm{mmol})$ and the mixture was stirred first at $-10{ }^{\circ} \mathrm{C}$ and then at room temperature for $6 \mathrm{~h}$. The reaction mixture was neutralized by the addition of $1 \mathrm{~N}$ citric acid to $\mathrm{pH}$ 6-7 and the solvent was removed to leave a residue of 21 which was dried in vacuo overnight.

To a suspension of 21 in THF $(60 \mathrm{~mL})$ at $-10{ }^{\circ} \mathrm{C}$ was added $\mathrm{Et}_{3} \mathrm{~N}(0.54 \mathrm{~mL}, 3.9 \mathrm{mmol})$ and methyl chloroformate $(0.3 \mathrm{~mL}, 3.9 \mathrm{mmol})$, and the mixture was stirred at room temperature for $60 \mathrm{~h}$. After removal of the solvent in vacuo, the residue was diluted with EtOAc and $\mathrm{H}_{2} \mathrm{O}$, the layers were separated, and the aqueous layer was extracted with EtOAc twice. The combined organic extract was washed with brine, dried over $\mathrm{Na}_{2} \mathrm{SO}_{4}$, and concentrated in vacuo. Flash chromatography (hexane-ethyl acetate, $1: 1)$ of the residue afforded $110 \mathrm{mg}(61 \%)$ of a primary alcohol: $[\alpha]_{\mathrm{D}}^{23}+25.6\left(c 1.8 \mathrm{CHCl}_{3}\right) ; \mathrm{IR}$ (neat) $3457,2984,2924,1770,1453,1372,1214,1057,984,855 \mathrm{~cm}^{-1} ;{ }^{1} \mathrm{H}$ NMR (400 MHz, $\left.\mathrm{CDCl}_{3}\right)$ $\delta 1.38(\mathrm{~s}, 3 \mathrm{H}), 1.44(\mathrm{~s}, 3 \mathrm{H}), 1.68(\mathrm{~m}, 1 \mathrm{H}), 1.75(\mathrm{~s}, 3 \mathrm{H}), 2.22(\mathrm{~m}, 2 \mathrm{H}), 2.52(\mathrm{~m}, 1 \mathrm{H}), 3.16(\mathrm{t}, J=9.8 \mathrm{~Hz}$ 
$1 \mathrm{H}), 3.58(\mathrm{t}, J=8.0 \mathrm{~Hz}, 1 \mathrm{H}), 3.79(\mathrm{dd}, J=7.4,12.4 \mathrm{~Hz}, 1 \mathrm{H}), 3.86(\mathrm{dd}, J=4.3,11.5 \mathrm{~Hz}, 1 \mathrm{H}), 4.01(\mathrm{dd}, J$ $=6.1,8.2 \mathrm{~Hz}, 1 \mathrm{H}), 4.38-4.41(\mathrm{~m}, 1 \mathrm{H}), 5.02(\mathrm{t}, J=7.4 \mathrm{~Hz}, 1 \mathrm{H}) ;{ }^{13} \mathrm{C} \mathrm{NMR}\left(100 \mathrm{Mz}, \mathrm{CDCl}_{3}\right) \delta 15.1$, 21.9, 25.3, 25.9, 26.7, 47.5, 48.0, 61.4, 67.8, 69.0, 74.1, 109.6, 127.2, 130.0 179.3; HRMS (FAB) $m / z$ 282.1473(calcd for $\mathrm{C}_{15} \mathrm{H}_{22} \mathrm{O}_{5}, 282.1467$ ).

To a solution of oxalyl chloride $(32 \mu 1,0.36 \mathrm{mmol})$ in $\mathrm{CH}_{2} \mathrm{Cl}_{2}(0.5 \mathrm{~mL})$ at $-78{ }^{\circ} \mathrm{C}$ was added a solution of DMSO $(51 \mu \mathrm{l}, 0.72 \mathrm{mmol})$ in $\mathrm{CH}_{2} \mathrm{Cl}_{2}(0.4 \mathrm{~mL})$. The mixture was stirred for $5 \mathrm{~min}$, and a solution of the alcohol obtained above $(68.5 \mathrm{mg}, 0.24 \mathrm{mmol})$ in $\mathrm{CH}_{2} \mathrm{Cl}_{2}(1.8 \mathrm{~mL})$ was added. The mixture was stirred for $10 \mathrm{~min}$ at $-78{ }^{\circ} \mathrm{C}, \mathrm{Et}_{3} \mathrm{~N}(0.17 \mathrm{ml}, 1.2 \mathrm{mmol})$ was added, and the mixture was allowed to warm to room temperature slowly. The reaction was quenched by addition of saturated aqueous $\mathrm{NaHCO}_{3}$, and the mixture was diluted with $\mathrm{CH}_{2} \mathrm{Cl}_{2}$. The phases were separated, the aqueous phase was extracted with $\mathrm{CH}_{2} \mathrm{Cl}_{2}$ twice, and the combined organic extract was washed with brine, dried over $\mathrm{Na}_{2} \mathrm{SO}_{4}$, and concentrated in vacuo. Flash chromatography (hexane-ethyl acetate, 4:1) of the residue afforded $60.5 \mathrm{mg}(89 \%)$ of 22 as colorless prisms: $\mathrm{mp} 118-121^{\circ} \mathrm{C} ;[\alpha]_{\mathrm{D}}^{23}-6.6\left(\mathrm{c} 1.1, \mathrm{CHCl}_{3}\right)$; IR (neat) 2933, 1782, 1716, 1455, 1371, 1212, 1155, 1055, 982, $856 \mathrm{~cm}^{-1} ;{ }^{1} \mathrm{H}$ NMR (300 MHz, $\left.\mathrm{CDCl}_{3}\right)$ $\delta 1.36(\mathrm{~s}, 3 \mathrm{H}), 1.43(\mathrm{~s}, 3 \mathrm{H}), 1.76(\mathrm{~d}, J=1.7 \mathrm{~Hz}, 3 \mathrm{H}), 1.92(\mathrm{~m}, 1 \mathrm{H}), 2.32(\mathrm{~m}, 1 \mathrm{H}), 2.60(\mathrm{~m}, 2 \mathrm{H}), 3.24(\mathrm{~m}$ 1H), $3.55(\mathrm{t}, J=7.9 \mathrm{~Hz}, 1 \mathrm{H}), 4.03(\mathrm{~d}, J=6.9,8.3 \mathrm{~Hz}, 1 \mathrm{H}), 4.55(\mathrm{~m}, 2 \mathrm{H}), 5.00(\mathrm{t}, J=7.7 \mathrm{~Hz}, 1 \mathrm{H}), 9.6$ $(\mathrm{d}, J=1.3 \mathrm{~Hz}, 1 \mathrm{H}) ;{ }^{13} \mathrm{C} \mathrm{NMR}\left(100 \mathrm{Mz}, \mathrm{CDCl}_{3}\right) \delta 15.3,22.2,24.3,25.7,26.7,47.8,67.8,69.0,74.1$, 77.0, 109.8, 127.0, 132.1, 180.2, 196.4; HRMS (FAB) $m / z 279.1232\left([\mathrm{M}-\mathrm{H}]^{+}\right.$; calcd for $\mathrm{C}_{15} \mathrm{H}_{20} \mathrm{O}_{5}$, 279.1233).

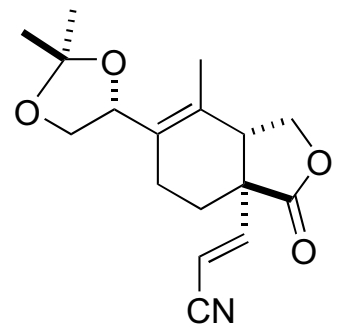

23

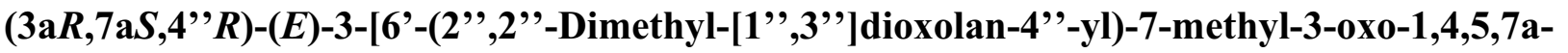
tetrahydroisobenzofuran-3a-yl]acrylonitrile (23). To a solution of diethyl (cyanomethyl)phosphonate 
$(0.12 \mathrm{~mL}, 0.74 \mathrm{mmol})$ in $\mathrm{THF}(0.8 \mathrm{~mL})$ at $0{ }^{\circ} \mathrm{C}$ was added $n$-BuLi $(0.16 \mathrm{~mL}$ of a $2.2 \mathrm{M}$ solution in hexane, $0.35 \mathrm{mmol}$ ). The mixture was stirred at $0{ }^{\circ} \mathrm{C}$ for $20 \mathrm{~min}$ and at room temperature for $20 \mathrm{~min}$. The mixture was then cooled to $0{ }^{\circ} \mathrm{C}$, and a solution of $22(50.2 \mathrm{mg}, 0.18 \mathrm{mmol})$ in $\mathrm{THF}(1.0 \mathrm{~mL})$ was added. The resulting solution was allowed to warm to room temperature and stirring was continued for $2 \mathrm{~h}$. The reaction was quenched by addition of saturated aqueous $\mathrm{NaHCO}_{3}$, and the mixture was diluted with EtOAc. The layers were separated, the aqueous layer was extracted with EtOAc twice, and the combined organic extract was washed with brine, dried over $\mathrm{Na}_{2} \mathrm{SO}_{4}$, and concentrated under vacuum. The residue was purified by chromatography (hexane-EtOAc, $2: 1)$ to give $46.5 \mathrm{mg}(85 \%)$ of $23:[\alpha]_{\mathrm{D}}^{23}$ +1.8 (c $\left.1.0 \mathrm{CHCl}_{3}\right)$; IR (neat) 2923, 2853, 2226, 1778, 1458, $13721210,1155,1110,1056,978,858$ $\mathrm{cm}^{-1} ;{ }^{1} \mathrm{H}$ NMR $\left(400 \mathrm{MHz}, \mathrm{CDCl}_{3}\right) \delta 1.39(\mathrm{~s}, 3 \mathrm{H}), 1.45(\mathrm{~s}, 3 \mathrm{H}), 1.75(\mathrm{~s}, 3 \mathrm{H}), 1.91(\mathrm{~m}, 1 \mathrm{H}), 2.18(\mathrm{~m}, 1 \mathrm{H})$, $2.22(\mathrm{~m}, 1 \mathrm{H}), 2.45(\mathrm{~m}, 1 \mathrm{H}), 3.13(\mathrm{~m}, 1 \mathrm{H}), 3.55(\mathrm{t}, J=8.0 \mathrm{~Hz}, 1 \mathrm{H}), 4.03(\mathrm{t}, J=8.4 \mathrm{~Hz}, 1 \mathrm{H}), 4.06(\mathrm{dd}, J=$ 3.3, 8.7 Hz, 1H), $4.45(\mathrm{dd}, J=6.7,8.5 \mathrm{~Hz}, 1 \mathrm{H}), 5.03$ (t, $J=7.4 \mathrm{~Hz}, 1 \mathrm{H}), 5.66(\mathrm{~d}, J=17.1 \mathrm{~Hz}, 1 \mathrm{H}), 6.88$ $(\mathrm{d}, J=17.1 \mathrm{~Hz}, 1 \mathrm{H}) ;{ }^{13} \mathrm{C} \mathrm{NMR}\left(100 \mathrm{Mz}, \mathrm{CDCl}_{3}\right) \delta 15.2,21.9,25.5,26.6,28.9,48.6,49.5,67.6,68.5$, 73.9, 105.0, 109.7. 116.4, 125.2. 131.5, 148.8, 175.4; HRMS (CI) $m / z 303.1470$ (calcd for $\mathrm{C}_{17} \mathrm{H}_{21} \mathrm{O}_{4} \mathrm{~N}$ : $303.1471)$

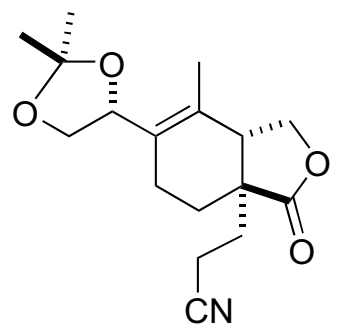

24

$(3 a R, 7 \mathrm{a} S, 4$ ' $R)-3-[6$ '-(2',,2',-Dimethyl-[1',3']dioxolan-4''-yl)-7-methyl-3-oxo-1,4,5,7atetrahydroisobenzofuran-3a-yl]propionitrile (24). To a solution of 23 (7 $\mathrm{mg}$ ) in a mixture of EtOH $(0.2 \mathrm{~mL})$, EtOAc $(0.2 \mathrm{~mL})$ and $\mathrm{Et}_{2} \mathrm{NH}(40 \mu \mathrm{L})$ at $0^{\circ} \mathrm{C}$ was added $\mathrm{pd} / \mathrm{C}(4 \mathrm{mg}, 5 \%)$. The mixture was stirred for $3 \mathrm{~h}$ at room temperature under a $\mathrm{H}_{2}$ atmosphere and then filtered. The filtrate was concentrated in vacuo and the residue was purified by chromatography (hexane-EtOAc, 3:1) to give 4.9 $\operatorname{mg}(71 \%)$ of 24: $[\alpha]_{\mathrm{D}}^{23}+29.2\left(c 0.24, \mathrm{CHCl}_{3}\right)$; IR (neat) 2928, 2248, 1766, 1453, 1371, 1260, 1212, 
1156, 1056, 1028, 859, $799 \mathrm{~cm}^{-1} ;{ }^{1} \mathrm{H}$ NMR (400 MHz, $\left.\mathrm{CDCl}_{3}\right) \delta 1.43(\mathrm{~s}, 3 \mathrm{H}), 1.49(\mathrm{~s}, 3 \mathrm{H}), 1.75(\mathrm{~s}, 3 \mathrm{H})$, $1.69-1.79(\mathrm{~m}, 2 \mathrm{H}), 2.11-2.34(\mathrm{~m}, 3 \mathrm{H}), 2.49(\mathrm{~m}, 2 \mathrm{H}), 3.16(\mathrm{~m}, 1 \mathrm{H}), 3.59(\mathrm{t}, J=8.0 \mathrm{~Hz}, 1 \mathrm{H}), 4.07(\mathrm{dd}$, $J=6.9,8.0 \mathrm{~Hz}, 1 \mathrm{H}), 4.25(\mathrm{dd}, J=8.7,12.1 \mathrm{~Hz}, 1 \mathrm{H}), 4.46(\mathrm{t}, J=7.8 \mathrm{~Hz}, 1 \mathrm{H}), 5.05(\mathrm{t}, J=7.2 \mathrm{~Hz}, 1 \mathrm{H})$; ${ }^{13} \mathrm{C}$ NMR $\left(100 \mathrm{Mz}, \mathrm{CDCl}_{3}\right) \delta 12.7,15.2,21.8,22.2,25.3,25.8,26.7,44.0,49.1,67.8,68.1,74.0,109.8$, 119.5, 126.0, 130.3, 178.1; HRMS (FAB) $m / z 305.1620$ ([M] $]^{+}$; calcd for $\mathrm{C}_{17} \mathrm{H}_{23} \mathrm{O}_{4} \mathrm{~N}$ : 305.1627).

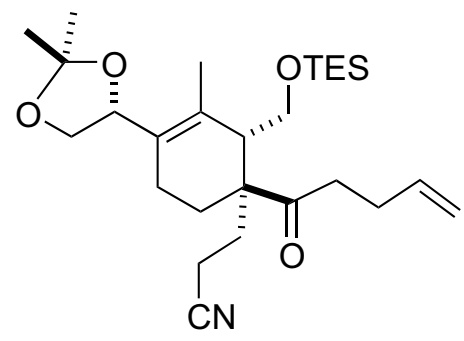

26

$(3 R, 2$ 'S,4''R)-3-[4'-(2', 2'’-Dimethyl-[1',,3',]dioxolan-4''-yl)-3'-methyl-1'-pent-4'-enoyl-2'triethylsilanyloxymethylcyclohex-3'-enyl]propionitrile (26). To a solution of $24(3.0 \mathrm{mg}, 0.01$ mmol $)$ in $\mathrm{Et}_{2} \mathrm{O}(0.1 \mathrm{~mL})$ at $-78{ }^{\circ} \mathrm{C}$ was added a solution of vinyllithium $(13 \mu \mathrm{L}$ of $1.58 \mathrm{M}$ solution in $\mathrm{Et}_{2} \mathrm{O}, 0.02 \mathrm{~mL}$ ) and the mixture was stirred for $1 \mathrm{~h}$. The reaction was quenched by addition of aqueous saturated $\mathrm{NH}_{4} \mathrm{Cl}$, and the mixture was diluted with $\mathrm{Et}_{2} \mathrm{O}$. The phases were separated, and the aqueous layer was extracted with $\mathrm{Et}_{2} \mathrm{O}$ twice. The combined organic extract was washed with saturated $\mathrm{NaHCO}_{3}$, brine, dried over $\mathrm{Na}_{2} \mathrm{SO}_{4}$, and concentrated under vacuum to give the crude lactol.

To a solution of the crude lactol in dry pyridine $(0.1 \mathrm{~mL})$ at $0{ }^{\circ} \mathrm{C}$ was added $\mathrm{TESCl}(5 \mu \mathrm{L}, 0.03$ mmol), and the mixture was stirred at room temperature for $10 \mathrm{~h}$. The reaction was quenched by addition of water, and the mixture was diluted with $\mathrm{Et}_{2} \mathrm{O}$. The phases were separated, and the aqueous layer was extracted with $\mathrm{Et}_{2} \mathrm{O}$ twice. The combined organic extract was washed with $\mathrm{H}_{2} \mathrm{O}$ and brine, dried over $\mathrm{Na}_{2} \mathrm{SO}_{4}$, and concentrated under vacuum. The residue was purified by chromatography (hexane-EtOAc, $3: 1)$ to give $1.5 \mathrm{mg}(32 \%)$ of 26: $[\alpha]_{\mathrm{D}}^{23}+30.8\left(c 0.12, \mathrm{CHCl}_{3}\right)$; IR (neat) 2954, 2933, $2875,2248,1702,1456,1379,1244,1063,1005,860,812,746 \mathrm{~cm}^{-1} ;{ }^{1} \mathrm{H}$ NMR $\left(300 \mathrm{MHz}, \mathrm{CDCl}_{3}\right) \delta$ $0.65(\mathrm{q}, J=7.8 \mathrm{~Hz}, 6 \mathrm{H}), 0.91(\mathrm{t}, J=7.8 \mathrm{~Hz}, 9 \mathrm{H}), 1.38(\mathrm{~s}, 3 \mathrm{H}), 1.43(\mathrm{~s}, 3 \mathrm{H}), 1.82(\mathrm{~s}, 3 \mathrm{H}), 1.75-2.23(\mathrm{~m}$, 
$10 \mathrm{H}), 2.55-2.65(\mathrm{~m}, 3 \mathrm{H}), 3.31(\mathrm{t}, J=8.0 \mathrm{~Hz}, 1 \mathrm{H}), 3.55(\mathrm{~d}, J=5.2 \mathrm{~Hz}, 2 \mathrm{H}), 3.95(\mathrm{dd}, J=6.8,8.1,1 \mathrm{H})$, $4.97(\mathrm{t}, J=7.4 \mathrm{~Hz}, 1 \mathrm{H}), 5.03(\mathrm{dd}, J=1.6,10.1 \mathrm{~Hz}, 1 \mathrm{H}), 5.09(\mathrm{dd}, J=1.6,17.1 \mathrm{~Hz}, 1 \mathrm{H}), 5.80(\mathrm{~m}, 1 \mathrm{H})$;

${ }^{13} \mathrm{C} \mathrm{NMR}\left(100 \mathrm{Mz}, \mathrm{CDCl}_{3}\right) \delta 1.4,4.6,7.3,13.2,19.3,21.0,25.8,26.7,26.9,28.0,32.6,46.8,53.8,62.4$, 67.3, 74.9, 109.4, 116.4, 120.1, 128.7, 131.0, 137.4, 211.7; HRMS (CI) $m / z$ 475.3128 ([M] $]^{+}$; calcd for $\mathrm{C}_{27} \mathrm{H}_{45} \mathrm{O}_{4} \mathrm{SiN}:$ 475.3118).

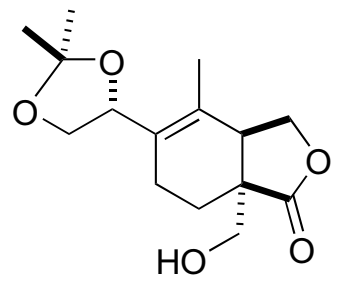

27

(3aS,7aR,4'R)-5-(2',2'-Dimethyl-[1',3']dioxolan-4'-yl)-7a-hydroxymethyl-4-methyl-3a,6,7,7atetrahydro-3H-isobenzofuran-1-one (27). To a solution of 15 (91 $\mathrm{mg}, 0.19 \mathrm{mmol})$ in a mixture of $\mathrm{CH}_{2} \mathrm{Cl}_{2}(2 \mathrm{~mL})$ and $\mathrm{pH} 7$ buffer $(0.1 \mathrm{~mL})$ at $0{ }^{\circ} \mathrm{C}$ under argon was added DDQ (55 mg, $\left.0.24 \mathrm{mmol}\right)$. The mixture was stirred for $8 \mathrm{~h}$ at room temperature, after which $\mathrm{NaHCO}_{3}$ powder $(70 \mathrm{mg}, 0.83 \mathrm{mmol})$ was added. Removal of the solvent left a residue that was dried in vacuo and then taken up in THF (6 $\mathrm{mL})$. To the suspension at $-10{ }^{\circ} \mathrm{C}$ was added $\mathrm{Et}_{3} \mathrm{~N}(0.16 \mathrm{ml}, 1.15 \mathrm{mmol})$ and methyl chloroformate $(90$ $\mu \mathrm{L}, 1.15 \mathrm{mmol}$ ), and the mixture was stirred at $-10{ }^{\circ} \mathrm{C}$ for $20 \mathrm{~min}$ and at room temperature for $20 \mathrm{~min}$. The mixture was then cooled to $-50{ }^{\circ} \mathrm{C}$, and a solution of $\mathrm{NaBH}_{4}(44 \mathrm{mg}, 1.15 \mathrm{mmol})$ in $\mathrm{MeOH}(0.28$ $\mathrm{mL}, 6.92 \mathrm{mmol}$ ) was added. The resulting mixture was stirred at $-35{ }^{\circ} \mathrm{C}$ for $1 \mathrm{~h}$ and the reaction was quenched at $-35^{\circ} \mathrm{C}$ by the addition of saturated aqueous $\mathrm{NH}_{4} \mathrm{Cl}$. The mixture was warmed to room temperature and diluted with EtOAc, the phases were separated, and the aqueous layer was extracted with EtOAc twice. The combined organic extract was washed with brine, dried over $\mathrm{Na}_{2} \mathrm{SO}_{4}$, and concentrated under vacuum. Flash chromatography (hexane-EtOAc, 1:1) of the residue afforded $39 \mathrm{mg}$ $(72 \%)$ of $27:[\alpha]_{\mathrm{D}}^{23}+99.0\left(c 1.6, \mathrm{CHCl}_{3}\right)$; IR (neat) 3460, 2983, 2927, 2875, 1767, 1454, 1380, 1265, 1212, 1157, 1056, 1031, $860 \mathrm{~cm}^{-1} ;{ }^{1} \mathrm{H}$ NMR (300 MHz, $\left.\mathrm{CDCl}_{3}\right) \delta 1.39(\mathrm{~s}, 3 \mathrm{H}), 1.44(\mathrm{~s}, 3 \mathrm{H}), 1.73(\mathrm{~s}$, $3 \mathrm{H}), 1.75-2.32(\mathrm{~m}, 4 \mathrm{H}), 2.92(\mathrm{t}, J=8.0 \mathrm{~Hz}, 1 \mathrm{H}), 3.52(\mathrm{t}, J=7.8 \mathrm{~Hz}, 1 \mathrm{H}), 3.63(\mathrm{dd}, J=5.1,11.1 \mathrm{~Hz}$, 
1H), $3.81(\mathrm{dd}, J=7.1,11.1 \mathrm{~Hz}, 1 \mathrm{H}), 3.90(\mathrm{dd}, J=8.0,8.5 \mathrm{~Hz}, 1 \mathrm{H}), 4.03$ (dd, $J=6.6,8.1 \mathrm{~Hz}, 1 \mathrm{H}), 4.57$

$(\mathrm{t}, J=8.6 \mathrm{~Hz}, 1 \mathrm{H}), 5.01(\mathrm{t}, J=7.4 \mathrm{~Hz}, 1 \mathrm{H}) ;{ }^{13} \mathrm{C} \mathrm{NMR}\left(100 \mathrm{Mz}, \mathrm{CDCl}_{3}\right) \delta 17.7,20.0,24.0,25.9,26.7$, calcd for $\left.\mathrm{C}_{15} \mathrm{H}_{22} \mathrm{O}_{5}, 282.1467\right)$.

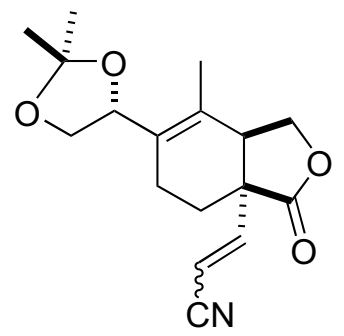

28

$(3 \mathrm{a} R, 7 \mathrm{a} R, 4$ '' $R)-3-[6$ '-(2', 2''-Dimethyl-[1',3'’]dioxolan-4''-yl)-7-methyl-3-oxo-1,4,5,7atetrahydroisobenzofuran-3a-yl]acrylonitrile (28). To a solution of oxalyl chloride (17 $\mu \mathrm{L}, 0.19$ mmol) in $\mathrm{CH}_{2} \mathrm{Cl}_{2}(0.2 \mathrm{~mL})$ at $-78{ }^{\circ} \mathrm{C}$ under argon was added a solution of DMSO $(39 \mu 1,0.39 \mathrm{mmol})$ in $\mathrm{CH}_{2} \mathrm{Cl}_{2}(0.2 \mathrm{~mL})$. The mixture was stirred for $5 \mathrm{~min}$, and a solution of $27(37.6 \mathrm{mg}, 0.13 \mathrm{mmol})$ in $\mathrm{CH}_{2} \mathrm{Cl}_{2}(1.0 \mathrm{~mL})$ was added. The resulting mixture was stirred for $10 \mathrm{~min}$ at $-78{ }^{\circ} \mathrm{C}, \mathrm{Et}_{3} \mathrm{~N}(90 \mu \mathrm{L}, 0.65$ mmol) was added, and the solution was allowed to warm to room temperature slowly. The reaction was quenched by the addition of saturated aqueous $\mathrm{NaHCO}_{3}$, and the mixture was diluted with $\mathrm{CH}_{2} \mathrm{Cl}_{2}$. The phases were separated, and the aqueous layer was extracted with $\mathrm{CH}_{2} \mathrm{Cl}_{2}$ twice. The combined organic extract was washed with brine, dried over $\mathrm{Na}_{2} \mathrm{SO}_{4}$, and concentrated under vacuum. Chromatography of the residue gave $33 \mathrm{mg}(88 \%)$ of the aldehyde: $[\alpha]_{\mathrm{D}}^{23}+61.8\left(c 1.0, \mathrm{CHCl}_{3}\right)$; IR (neat) $2924,2853,1768$, $1720,1457,1367,1210,1155,1056,1026,859 \mathrm{~cm}^{-1} ;{ }^{1} \mathrm{H}$ NMR $\left(300 \mathrm{MHz}, \mathrm{CDCl}_{3}\right) \delta 1.38(\mathrm{~s}, 3 \mathrm{H}), 1.43$ $(\mathrm{s}, 3 \mathrm{H}), 1.79(\mathrm{~s}, 3 \mathrm{H}), 2.01(\mathrm{~m}, 2 \mathrm{H}), 2.21(\mathrm{~m}, 2 \mathrm{H}), 3.35(\mathrm{t}, J=6.7 \mathrm{~Hz}, 1 \mathrm{H}), 3.51(\mathrm{t}, J=8.0 \mathrm{~Hz}, 1 \mathrm{H}), 4.02$ $(\mathrm{m}, 2 \mathrm{H}), 4.50(\mathrm{t}, J=8.2 \mathrm{~Hz}, 1 \mathrm{H}), 4.98(\mathrm{t}, J=7.2 \mathrm{~Hz}, 1 \mathrm{H}), 9.59(\mathrm{~s}, 1 \mathrm{H}) ;{ }^{13} \mathrm{C} \mathrm{NMR}\left(100 \mathrm{Mz}, \mathrm{CDCl}_{3}\right)$ $\delta 17.4,19.7,23.9,25.9,26.7,41.1,58.7,67.7,71.3,74.4,109.8,128.0,131.0,174.5,196.0 ;$ HRMS (CI) $m / z 280.1318\left([\mathrm{M}]^{+}\right.$; calcd for $\left.\mathrm{C}_{15} \mathrm{H}_{20} \mathrm{O}_{5}: 208.1311\right)$.

To a solution of diethyl (cyanomethyl)phosphonate $(0.12 \mathrm{~mL}, 0.74 \mathrm{mmol})$ in $\mathrm{THF}(0.5 \mathrm{~mL})$ at $0{ }^{\circ} \mathrm{C}$ was added $n$ - BuLi $(0.25 \mathrm{~mL}$ of $2.0 \mathrm{M}$ in hexane, $0.50 \mathrm{ml})$ and the mixture was stirred at $0{ }^{\circ} \mathrm{C}$ for $20 \mathrm{~min}$ and at room temperature for $20 \mathrm{~min}$. The mixture was cooled to $0{ }^{\circ} \mathrm{C}$, and a solution of the aldehyde 
obtained above $(70.5 \mathrm{mg}, 0.25 \mathrm{mmol})$ in THF $(1.0 \mathrm{~mL})$ was added. The resulting solution was allowed to warm to room temperature and stirring was continued for $2 \mathrm{~h}$. The reaction was quenched by addition of saturated aqueous $\mathrm{NaHCO}_{3}$, and the mixture was diluted with EtOAc. The layers were separated and the aqueous layer was extracted with EtOAc twice. The combined organic extract was washed with brine, dried over $\mathrm{Na}_{2} \mathrm{SO}_{4}$, and concentrated in vacuo. Chromatography of the residue gave $59.5 \mathrm{mg}(78 \%)$ of $\mathbf{2 8}$ as a $4: 1$ mixture of trans and cis-isomers.

Trans-isomer: $[\alpha]_{\mathrm{D}}^{23}+58.2\left(\mathrm{c} 1.37, \mathrm{CHCl}_{3}\right)$; IR (neat) 2986, 2226, 1769, 1372, 1211, 1185, 1156, 981, 859, $755 \mathrm{~cm}^{-1} ;{ }^{1} \mathrm{H}$ NMR $\left(300 \mathrm{MHz}, \mathrm{CDCl}_{3}\right) \delta 1.38(\mathrm{~s}, 3 \mathrm{H}), 1.44(\mathrm{~s}, 3 \mathrm{H}), 1.76(\mathrm{~s}, 3 \mathrm{H}), 1.82(\mathrm{~m}, 2 \mathrm{H})$, 2.11- $2.23(\mathrm{~m}, 2 \mathrm{H}), 2.82(\mathrm{t}, J=7.5 \mathrm{~Hz}, 1 \mathrm{H}), 3.50(\mathrm{t}, J=8.0 \mathrm{~Hz}, 1 \mathrm{H}), 3.94(\mathrm{t}, J=8.2 \mathrm{~Hz}, 1 \mathrm{H}), 4.04(\mathrm{dd}$, $J=6.7,8.2 \mathrm{~Hz}, 1 \mathrm{H}), 4.55(\mathrm{t}, J=8.6 \mathrm{~Hz}, 1 \mathrm{H}), 4.99(\mathrm{t}, J=7.2 \mathrm{~Hz}, 1 \mathrm{H}), 5.45(\mathrm{~d}, J=16.7 \mathrm{~Hz}, 1 \mathrm{H}), 6.80(\mathrm{~d}$, $J=16.7 \mathrm{~Hz}, 1 \mathrm{H}) ;{ }^{13} \mathrm{C} \mathrm{NMR}\left(100 \mathrm{Mz}, \mathrm{CDCl}_{3}\right) \delta 17.5,19.8,25.8,26.7,45.9,48.2,68.0,70.7,74.4,102.5$, 110.0, 116.7, 126.5, 131.9, 152.2, 176.7; HRMS (CI) $m / z 303.1486\left([\mathrm{M}]^{+}\right.$; calcd for $\mathrm{C}_{17} \mathrm{H}_{21} \mathrm{O}_{4} \mathrm{~N}$ : 303.1471).

Cis-isomer: $[\alpha]_{\mathrm{D}}^{23}+10.5$ (c 1.55, $\mathrm{CHCl}_{3}$ ); IR (neat) 2985, 2220, 1769, 1372, 1213, 1183, 1157 , 1026, 859, $740 \mathrm{~cm}^{-1} ;{ }^{1} \mathrm{H}$ NMR $\left(300 \mathrm{MHz}, \mathrm{CDCl}_{3}\right) \delta 1.42(\mathrm{~s}, 3 \mathrm{H}), 1.48(\mathrm{~s}, 3 \mathrm{H}), 1.79(\mathrm{~s}, 3 \mathrm{H}), 1.85(\mathrm{~m}$, 1H), $1.95(\mathrm{~m}, 1 \mathrm{H}), 2.19(\mathrm{~m}, 1 \mathrm{H}), 3.46(\mathrm{~m}, 1 \mathrm{H}), 3.51(\mathrm{t}, J=8.0 \mathrm{~Hz}, 1 \mathrm{H}), 3.97(\mathrm{t}, J=8.6 \mathrm{~Hz}, 1 \mathrm{H}), 4.11$ $(\mathrm{dd}, J=6.7,8.0 \mathrm{~Hz}, 1 \mathrm{H}), 4.67(\mathrm{t}, J=7.3 \mathrm{~Hz}, 1 \mathrm{H}), 5.63(\mathrm{~d}, J=12.2 \mathrm{~Hz}, 1 \mathrm{H}), 6.54(\mathrm{~d}, J=12.2 \mathrm{~Hz}, 1 \mathrm{H})$; ${ }^{13} \mathrm{C} \mathrm{NMR}\left(100 \mathrm{Mz}, \mathrm{CDCl}_{3}\right) \delta 17.3,20.4,25.8,26.7,27.1,44.6,48.7,68.3,71.1,74.6,101.5,109.9$, 115.1, 127.3, 131.3, 150.8, 177.1; HRMS (CI) $m / z 303.1486$ ([M] $]^{+}$; calcd for $\left.\mathrm{C}_{17} \mathrm{H}_{21} \mathrm{O}_{4} \mathrm{~N}: 303.1471\right)$.

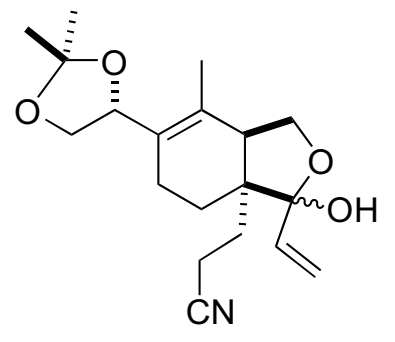

29

$(3 \mathrm{a} R, 7 \mathrm{a} R, 4$ ''R)-3-[6'-(2',,2',-Dimethyl-[1',,3',]dioxolan-4''-yl)-7-methyl-3-vinyl-1,4,5,7a- 
tetrahydro-sobenzofuran-3a-yl]propionitrile (29). To a solution of 28 (54 $\mathrm{mg}, 0.18 \mathrm{mmol})$ in $\mathrm{MeOH}$ (1.8 mL) was added $\mathrm{Mg}$ turnings $(24 \mathrm{mg}, 1 \mathrm{mmol})$. The mixture was stirred at $0{ }^{\circ} \mathrm{C}$ for $1 \mathrm{~h}$, then was stirred at room temperature for $5 \mathrm{~h}$. The mixture was poured into a cold solution of $\mathrm{HCl}(0.5 \mathrm{M}, 2 \mathrm{~mL})$ and diluted with $\mathrm{CH}_{2} \mathrm{Cl}_{2}$. The phases were separated and the aqueous layer was extracted with $\mathrm{CH}_{2} \mathrm{Cl}_{2}$ twice. The combined organic extract was washed with saturated $\mathrm{NaHCO}_{3}$ and brine, dried over $\mathrm{Na}_{2} \mathrm{SO}_{4}$, and concentrated under vacuum. The residue was purified by chromatography (hexane-EtOAc, 3:1) to give $48 \mathrm{mg}(86 \%)$ of the nitrile: $[\alpha]_{\mathrm{D}}^{23}+67.0\left(c 0.93, \mathrm{CHCl}_{3}\right)$; IR (neat) 2928, 2248, 1766, 1453, 1371, 1260, 1212, 1156, 1056, 1028, 859, $799 \mathrm{~cm}^{-1} ;{ }^{1} \mathrm{H}$ NMR (300 MHz, $\left.\mathrm{CDCl}_{3}\right) \delta 1.38(\mathrm{~s}, 3 \mathrm{H}), 1.44(\mathrm{~s}, 3 \mathrm{H})$, $1.72(\mathrm{~s}, 3 \mathrm{H}), 1.61-1.83(\mathrm{~m}, 2 \mathrm{H}), 2.00(\mathrm{~m}, 3 \mathrm{H}), 2.22(\mathrm{~m}, 1 \mathrm{H}), 2.45-2.65(\mathrm{~m}, 2 \mathrm{H}), 2.71(\mathrm{t}, J=7.7 \mathrm{~Hz}$ $1 \mathrm{H}), 3.50(\mathrm{t}, J=8.1 \mathrm{~Hz}, 1 \mathrm{H}), 3.93(\mathrm{dd}, \mathrm{J}=7.6,8.7 \mathrm{~Hz}, 1 \mathrm{H}), 4.03(\mathrm{dd}, J=5.7,8.1 \mathrm{~Hz}, 1 \mathrm{H}), 4.52(\mathrm{t}, J=$ $8.4 \mathrm{~Hz}, 1 \mathrm{H}), 5.00(\mathrm{t}, J=7.0 \mathrm{~Hz}, 1 \mathrm{H}) ;{ }^{13} \mathrm{C} \mathrm{NMR}\left(100 \mathrm{Mz}, \mathrm{CDCl}_{3}\right) \delta 12.5,17.7,19.9,25.7,25.9,26.7$, 29.9, 43.9, 46.8, 67.9, 70.7, 74.5, 109.8, 127.3, 130.9, 179.7; HRMS (FAB) $m / z ~ 305.1627$ ([M] $]^{+}$calcd for $\mathrm{C}_{17} \mathrm{H}_{23} \mathrm{O}_{4} \mathrm{~N}: 305.1624$ ).

To a solution of tdhe nitrile prepared above $(35 \mathrm{mg}, 0.11 \mathrm{mmol})$ in $\mathrm{Et}_{2} \mathrm{O}(1.0 \mathrm{~mL})$ at $-78{ }^{\circ} \mathrm{C}$ was added a solution of vinyllithium $\left(1.1 \mathrm{~mL}\right.$ of a $1.43 \mathrm{M}$ solution in $\left.\mathrm{Et}_{2} \mathrm{O}, 1.57 \mathrm{~mL}\right)$ and the mixture was stirred at $-78{ }^{\circ} \mathrm{C}$ for $1 \mathrm{~h}$. The reaction was quenched by addition of saturated aqueous $\mathrm{NH}_{4} \mathrm{Cl}$ and the mixture was diluted with $\mathrm{Et}_{2} \mathrm{O}$. The phases were separated and the aqueous layer was extracted with $\mathrm{Et}_{2} \mathrm{O}$ twice. The combined organic extract was washed with saturated $\mathrm{NaHCO}_{3}$ and brine, dried over $\mathrm{Na}_{2} \mathrm{SO}_{4}$, and concentrated under vacuum. The residue was purified by chromatography (hexaneEtOAc, $2: 1)$ to give $24 \mathrm{mg}(63 \%)$ of 29 as a 10:1 mixture of diastereomers: IR (neat) 3412, 2984, 2932, 2883, 2244, 1455, 1379, 1247, 1210, 1156, 1058, 999, 938, 862, $792 \mathrm{~cm}^{-1} ;{ }^{1} \mathrm{H}$ NMR $\left(300 \mathrm{MHz}, \mathrm{CDCl}_{3}\right)$ $\delta$ (major isomer) $1.40(\mathrm{~s}, 3 \mathrm{H}), 1.46(\mathrm{~s}, 3 \mathrm{H}), 1.65(\mathrm{~s}, 3 \mathrm{H}), 1.60-1.70(\mathrm{~m}, 1 \mathrm{H}), 1.86(\mathrm{~m}, 1 \mathrm{H}), 1.95-2.08$ $(\mathrm{m}, 3 \mathrm{H}), 2.38(\mathrm{~m}, 2 \mathrm{H}), 2.50(\mathrm{~s}, 1 \mathrm{H}, \mathrm{OH}), 2.65(\mathrm{t}, J=9.1,1 \mathrm{H}), 3.57(\mathrm{t}, J=8.1 \mathrm{~Hz}, 1 \mathrm{H}), 3.54(\mathrm{t}, J=8.0$ $\mathrm{Hz}, 1 \mathrm{H}), 4.04(\mathrm{dd}, J=6.7,8.0 \mathrm{~Hz}, 1 \mathrm{H}), 4.31(\mathrm{dd}, J=7.9,9.6 \mathrm{~Hz}, 1 \mathrm{H}), 5.02(\mathrm{t}, J=7.2 \mathrm{~Hz}, 1 \mathrm{H}), 5.34(\mathrm{dd}$, $J=1.2,10.7 \mathrm{~Hz}, 1 \mathrm{H}), 5.55(\mathrm{dd}, J=1.2,17.2 \mathrm{~Hz}, 1 \mathrm{H}), 5.95(\mathrm{dd}, J=10.7,17.2 \mathrm{~Hz}, 1 \mathrm{H}) ;{ }^{13} \mathrm{C} \mathrm{NMR}$ 
$\left(100 \mathrm{Mz}, \mathrm{CDCl}_{3}\right) \delta$ (major isomer) $12.6,18.8,20.4,23.8,25.7,26.6,26.7,47.9,49.4,68.0,72.2,74.7$, $106.9,109.5,118.4,120.5,127.0,129.2,138.0$; HRMS (CI) $\mathrm{m} / z 332.1869$ ([M-H] $]^{+}$; calcd for $\left.\mathrm{C}_{19} \mathrm{H}_{26} \mathrm{O}_{4} \mathrm{~N}: 332.1862\right)$.

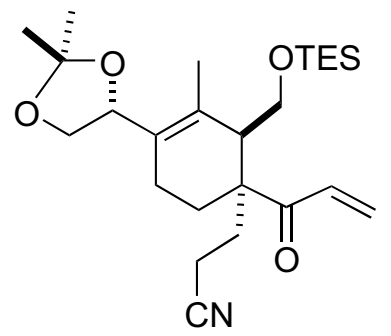

30

\section{$(3 R, 2 ' R, 4$,'R)-3-[1'-Acryloyl-4'-(2',2''-dimethyl-[1',3']dioxolan-4''-yl)-3'-methyl-2'-}

triethylsilanyloxymethyl-yclohex-3'-enyl]propionitrile (30). To a solution of 29 (7.4 mg, 0.022 mmol $)$ in dry pyridine $(0.2 \mathrm{~mL})$ at $0{ }^{\circ} \mathrm{C}$ was added TESCl $(15 \mu \mathrm{L}, 0.089 \mathrm{mmol})$ and the mixture was stirred at room temperature for $10 \mathrm{~h}$. The reaction was quenched by addition of water, and the mixture was diluted with $\mathrm{Et}_{2} \mathrm{O}$. The phases were separated, and the aqueous layer was extracted with $\mathrm{Et}_{2} \mathrm{O}$ twice. The combined organic extract was washed with water and brine, dried over $\mathrm{Na}_{2} \mathrm{SO}_{4}$, and concentrated under vacuum. The residue was purified by chromatography (hexane-EtOAc, 3:1) to give $6.8 \mathrm{mg}(68 \%)$ of $\mathbf{3 0}:[\alpha]_{\mathrm{D}}^{23}-77.1\left(c 0.65, \mathrm{CHCl}_{3}\right)$; IR (neat) 2952, 2931, 2875, 2245, 1693, 1456, 1401, $1379,1243,1154,1101,1061,1009,861,816,745 \mathrm{~cm}^{-1} ;{ }^{1} \mathrm{H}$ NMR $\left(300 \mathrm{MHz}, \mathrm{CDCl}_{3}\right) \delta 0.55(\mathrm{q}, J=7.8$ $\mathrm{Hz}, 6 \mathrm{H}), 0.91(\mathrm{t}, J=7.9 \mathrm{~Hz}, 9 \mathrm{H}), 1.43(\mathrm{~s}, 3 \mathrm{H}), 1.49(\mathrm{~s}, 3 \mathrm{H}), 1.82(\mathrm{~s}, 3 \mathrm{H}), 1.80-2.22(\mathrm{~m}, 8 \mathrm{H}), 3.44-$ $3.55(\mathrm{~m}, 3 \mathrm{H}), 4.05(\mathrm{dd}, J=6.8,7.9 \mathrm{~Hz}, 1 \mathrm{H}), 4.99(\mathrm{t}, J=7.2 \mathrm{~Hz}, 1 \mathrm{H}), 5.61(\mathrm{dd}, J=1.7,10.4 \mathrm{~Hz}, 1 \mathrm{H})$, $6.30(\mathrm{dd}, J=1.7,16.9 \mathrm{~Hz}, 1 \mathrm{H}), 6.86(\mathrm{dd}, J=10.4,16.9 \mathrm{~Hz}, 1 \mathrm{H}) ;{ }^{13} \mathrm{C} \mathrm{NMR}\left(100 \mathrm{Mz}, \mathrm{CDCl}_{3}\right) \delta 4.4,7.1$, $12.6,19.6,19.8,20.6,26.0,26.8,29.1,50.6,53.1,63.3,68.1,75.1,109.7,119.7,126.9,127.9,129.2$, 132.9, 201.9; HRMS (CI) $m / z 446.2732$ ([M-H] $]^{+}$; calcd for $\mathrm{C}_{25} \mathrm{H}_{40} \mathrm{O}_{4} \mathrm{SiN}$ : 446.2727). 


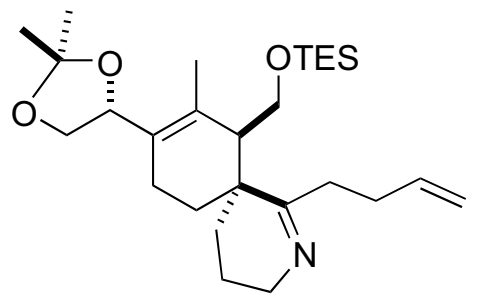

34

\section{$\left(6 R, 7 R, 4^{\prime} R\right)-1-B u t-3-e n y l-9-\left(2^{\prime}, 2 '-d i m e t h y l-\left[1^{\prime}, 3^{\prime}\right]\right.$ dioxolan-4'-yl)-8-methyl-7-triethyl-}

silanyloxymethyl-2-azaspiro[5.5] undeca-1,8-diene (34). To a solution of 2-thienyl(cyano)copper lithium $(100 \mu \mathrm{L}$ of a $0.25 \mathrm{M}$ solution in THF, $0.025 \mathrm{mmol})$ at $-78{ }^{\circ} \mathrm{C}$ was added vinyllithium $(20 \mu \mathrm{L}$ of a $1.25 \mathrm{M}$ solution in $\left.\mathrm{Et}_{2} \mathrm{O}, 0.025 \mathrm{mmol}\right)$, followed by a solution of 30 ( $\left.3 \mathrm{mg}, 0.0067 \mathrm{mmol}\right)$ in $\mathrm{THF}(0.2$ $\mathrm{mL})$. The mixture was stirred for $1.5 \mathrm{~h}$ at $-78{ }^{\circ} \mathrm{C}$ and $\mathrm{TMSCl}(5 \mu \mathrm{L}, 0.040 \mathrm{mmol})$ was added to the reaction mixture. The resulting solution was stirred at $-78{ }^{\circ} \mathrm{C}$ for $20 \mathrm{~min}$. The reaction was quenched by addition of saturated aqueous $\mathrm{NaHCO}_{3}$, and the mixture was diluted with EtOAc. The phases were separated, and the aqueous layer was extracted with EtOAc twice. The combined organic extract was washed with saturated $\mathrm{NaHCO}_{3}$ and brine, dried over $\mathrm{Na}_{2} \mathrm{SO}_{4}$, and concentrated in vacuo to give crude silyl enol ether 32.

To a solution of crude 32 in $\mathrm{Et}_{2} \mathrm{O}(0.2 \mathrm{~mL})$ at $0{ }^{\circ} \mathrm{C}$ was added $\mathrm{LiAlH}_{4}(95 \%, 1.8 \mathrm{mg}, 0.045 \mathrm{mmol})$ and the mixture was stirred at $0{ }^{\circ} \mathrm{C}$ for $10 \mathrm{~min}$. The reaction was quenched by the addition of water $(5$ $\mu \mathrm{L}), 15 \% \mathrm{NaOH}(5 \mu \mathrm{L})$, and water again $(15 \mu \mathrm{L})$. The resulting mixture was stirred for 30 min, then was filtered through Celite. The filtrate was dried over $\mathrm{Na}_{2} \mathrm{SO}_{4}$ and concentrated under vacuum. The residue was purified by chromatography $\left(\mathrm{CH}_{2} \mathrm{Cl}_{2}-\mathrm{MeOH}, 10: 1\right)$ to give $0.9 \mathrm{mg}$ (29\%) of 34: IR (neat)

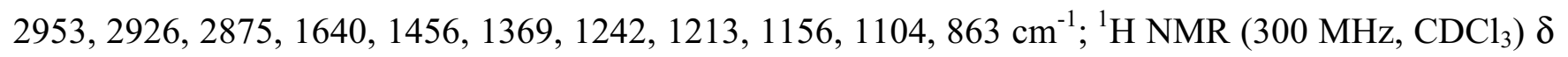
$0.55(\mathrm{q}, J=7.7 \mathrm{~Hz}, 6 \mathrm{H}), 0.90(\mathrm{t}, J=7.7 \mathrm{~Hz}, 9 \mathrm{H}), 1.41(\mathrm{~s}, 3 \mathrm{H}), 1.46(\mathrm{~s}, 3 \mathrm{H}), 1.75(\mathrm{~s}, 3 \mathrm{H}), 3.40-3.70(\mathrm{~m}$, 4H), $3.75(\mathrm{dd}, J=5.1,11.2 \mathrm{~Hz}, 1 \mathrm{H}), 4.03(\mathrm{dd}, J=7.7,8.0 \mathrm{~Hz}, 1 \mathrm{H}), 4.95-5.10(\mathrm{~m}, 3 \mathrm{H}), 5.90(\mathrm{~m}, 1 \mathrm{H})$; HRMS (FAB) $m / z 462.3395$ ([M+H] $]^{+}$; calcd for $\mathrm{C}_{27} \mathrm{H}_{48} \mathrm{O}_{3} \mathrm{SiN}$ : 462.3404). 